\title{
PONTUALIDADE NA OPERAÇÃO DE SEMEADURA E A ANTECIPAÇÃO DA ADUBAÇÃO E SUAS INFLUÊNCIASS NA RECEITA LÍQUIDA DA CULTURA DA SOJA
}

\author{
MARCOS A. MATOS ${ }^{1}$, JOSÉ V. SALVI ${ }^{2}$, MARCOS MILAN ${ }^{3}$
}

\begin{abstract}
RESUMO: A cultura da soja tem papel fundamental na economia do País, e estudos sobre os fatores que afetam sua produtividade, apresentam grande importância; um desses fatores está relacionado com a interação entre a época de semeadura e a produtividade da cultura. Os atrasos durante a operação de semeadura resultam em decréscimos na produtividade, e uma das razões para a sua ocorrência é a necessidade de aplicar grandes quantidades de adubo no momento da implantação da cultura. Essas grandes quantidades implicam maior tempo e número de abastecimentos da semeadora, influindo na sua capacidade operacional, sendo uma das alternativas para contornar o problema, antecipar a adubação, realizando-a na cultura anterior. Dessa forma, o objetivo deste trabalho foi avaliar a influência da realização da adubação fora do período da semeadura na receita líquida da cultura. Para tanto, foi desenvolvido um modelo empírico, em planilha eletrônica, para simular os efeitos do uso de diferentes cultivares, épocas de semeadura e sistemas de produção na receita líquida. Os resultados mostraram que, para o cenário analisado, a antecipação da adubação permite racionalização no dimensionamento das máquinas, reduzindo o número de conjuntos necessários à semeadura e aumentando a receita líquida da cultura.
\end{abstract}

PALAVRAS-CHAVE: mecanização agrícola, modelo, custos.

\section{SOWING OPERATION PUNCTUALITY AND ANTICIPATION OF FERTILIZING AND THEIR INFLUENCE ON SOYBEAN CROP PROFITS}

\begin{abstract}
Soybean crop plays a fundamental role in country economy, and studies on the factors that have an effect on its yields have major importance. One of these factors is related to the interaction between sowing time and crop yield. Delays during sowing operation result in yield decreases and one of the reasons for that are the necessity to apply a great quantity of fertilizer at crop establishment. These great quantities imply on longer loading time of drill, affecting its operation capacity. One way to overcome this problem is to anticipate fertilizing, carrying it out on the previous crop. Therefore, this paper aimed to evaluate the influence of fertilizing out of sowing time on soybean crop profits. In order to achieve this, an empirical model in electronic spreadsheet, was developed to simulate the effects of using different cultivars, sowing periods and productions systems on the profits. The results showed that, for the analyzed scene, fertilizing anticipation promotes rationalization of planning agricultural machinery, reducing the number of machinery necessary to sowing operation and increase crop profits.
\end{abstract}

KEYWORDS: agricultural mechanization, model, costs.

\section{INTRODUÇÃO}

O Brasil é o segundo maior produtor mundial de soja, com produção de 53 milhões de toneladas na safra 2004-2005, ficando à frente da Argentina e perdendo apenas para os Estados Unidos. O País consolidou-se como segundo maior exportador mundial de soja em grão, farelo e óleo, o que representou aproximadamente US\$ 10 bilhões em divisas, colocando a soja em primeiro lugar na pauta de exportações (ABIOVE, 2005).

\footnotetext{
${ }^{1}$ Eng $^{\mathrm{o}}$ Agrônomo, Mestrando do Curso de Pós-Graduação em Máquinas Agrícolas, Departamento de Engenharia Rural, Escola Superior de Agricultura “Luiz de Queiroz”, USP, Piracicaba - SP, Fone (0XX19) 3429.4165 - R: 230/233, mamatos@ esalq.usp.br

2 Eng ${ }^{\circ}$ Agrônomo, Mestrando do Curso de Pós-Graduação em Máquinas Agrícolas, Departamento de Engenharia Rural, Escola Superior de Agricultura "Luiz de Queiroz", USP, Piracicaba - SP.

${ }^{3}$ Eng ${ }^{0}$ Agrônomo, Professor Associado, Departamento de Engenharia Rural, Escola Superior de Agricultura "Luiz de Queiroz", USP, Piracicaba - SP.

Recebido pelo Conselho Editorial em: 9-8-2005
}

Aprovado pelo Conselho Editorial em: 17-5-2006 
Considerando-se essa importância da cultura, são necessários estudos sobre os fatores que diminuem a sua produtividade. A soja é uma planta sensível ao fotoperiodismo e, em resposta às variações do fotoperíodo no ambiente, ocorre a mudança da fase vegetativa para a reprodutiva. Os atrasos na operação de semeadura resultam na redução do período de vegetação e da produtividade, porque, à medida que ocorre o atraso na instalação da cultura, o final do período juvenil da cultivar aproxima-se da data de ocorrência daquele dia em que, na região de adaptação, a planta se encontra apta para a fase reprodutiva (CÂMARA, 2000).

De acordo com AGRIANUAL (2005), a redução observada no preço da saca da soja em duas safras analisadas foi seguida pela elevação na participação do custo envolvendo a mecanização em semeadura direta, atingindo $25,5 \%$ do custo total na safra 2004-2005, para a região Noroeste do Mato Grosso (Tabela 1). Devido à participação da mecanização na cultura da soja, o planejamento da operação de semeadura e o dimensionamento do sistema mecanizado são de extrema importância, considerando a influência do período de semeadura na produtividade da cultura (EMBRAPA, 1997).

TABELA 1. Custos de produção de soja no Mato Grosso, em semeadura direta, para produtividade de $3 \mathrm{t} \mathrm{ha}^{-1}$.

\begin{tabular}{|c|c|c|c|c|}
\hline \multirow{2}{*}{ Itens Levantados } & \multicolumn{2}{|c|}{ Safra 2003-2004 } & \multicolumn{2}{|c|}{ Safra 2004-2005 } \\
\hline & Valores & Participação (\%) & Valores & Participação (\%) \\
\hline Operações mecanizadas (R $\$$ ) & 280,10 & 21,4 & 351,50 & 25,5 \\
\hline Insumos (R\$) & 901,70 & 64,7 & 841,80 & 61,1 \\
\hline Administração $(\mathrm{R} \$)$ & 98,90 & 7,1 & 90,40 & 6,6 \\
\hline Pós-colheita (R\$) & 95,20 & 6,8 & 94,10 & 6,8 \\
\hline Custo total $(\mathrm{R} \$)$ & $1.375,90$ & 100,0 & $1.377,80$ & 100,0 \\
\hline Receita $\left(\mathrm{R} \$ \mathrm{ha}^{-1}\right)$ & $2.018,00$ & - & $1.026,70$ & - \\
\hline Preço da saca $(\mathrm{R} \$)$ & 41,50 & - & 22,00 & - \\
\hline Resultado ( $\left.\mathrm{R} \$ \mathrm{ha}^{-1}\right)$ & 642,00 & - & $-351,10$ & - \\
\hline
\end{tabular}

Fonte: AGRIANUAL (2005)

A diminuição na receita líquida devido a atrasos nas operações agrícolas foi demonstrada por VEIGA (2000), que avaliou os custos direto e indireto da mecanização na semeadura da soja em São Paulo, por meio da avaliação da diferença no custo de mecanização e na receita obtida, em função do período da semeadura.

Na região do cerrado brasileiro, responsável por 30\% da produção de soja do País, a cultura vem sendo implantada sob o sistema de semeadura direta. Os solos dessa região necessitam de grandes quantidades de fertilizantes, aplicados durante a operação de semeadura, implicando maior número de reabastecimentos da semeadora/adubadora, o que influi diretamente na redução da eficiência da operação. O aumento no tempo de operação pode gerar atrasos na implantação da cultura e, conseqüentemente, redução da produtividade, caracterizando o custo indireto da mecanização (MATOS et al., 2005). A inadequação da capacidade das máquinas em realizar a operação dentro dos prazos está associada ao conceito de pontualidade definido por BALASTREIRE (1987). Segundo o autor, a pontualidade é a "capacidade de efetuar as operações na época em que a qualidade e/ou quantidade de um produto são otimizadas". O levantamento das perdas por prazo de operação é extremamente útil para selecionar o número e o tamanho do maquinário agrícola necessário, sem que haja o superdimensionamento ou sobrecarga de trabalho (WITNEY, 1998).

A introdução de novas técnicas de cultivo, dentre as quais a consolidação do sistema de semeadura direta na região Centro-Oeste, tornou indispensável o aprimoramento de métodos de adubação, a fim de acompanhar a necessidade de constante crescimento da produtividade. Uma das alternativas que vem sendo testada é a antecipação da adubação da soja, que passa a ser realizada na cultura antecessora utilizada normalmente como adubo verde, prática essa que, segundo 
FRANCISCO (2002), não interfere na produtividade. O autor analisou a produtividade da cultura quando a adubação foi realizada a lanço e, antecipadamente na cultura do Eleusine coracana (L.) Gaertn., cultivada na primavera, em Sistema Plantio Direto. A antecipação promoveu aumento da produção de matéria seca, acúmulo de fósforo e cálcio no adubo verde, não interferindo na produtividade da soja.

Tendo em vista a importância da cultura da soja para o País, os riscos envolvidos com a pontualidade na semeadura, os custos da mecanização para a cultura e a possível influência dos tempos de recarga do adubo na semeadora/adubadora na pontualidade, este trabalho teve o objetivo de avaliar a influência da realização da adubação fora do período de semeadura, na receita líquida da cultura da soja.

\section{MATERIAL E MÉTODOS}

Para avaliar a influência da época da realização da adubação no desempenho operacional e econômico dos sistemas mecanizados (trator/semeadora) e na renda líquida da cultura da soja, foram definidos dois sistemas de produção. No primeiro sistema, denominado de Tradicional (TR), a adubação é realizada em conjunto com a semeadura. No segundo, denominado de Antecipação da Adubação (AA), a adubação é realizada na cultura do adubo verde semeada no final do inverno, antes da soja.

O sistema TR engloba as operações de semeadura e dessecamento do adubo verde, semeadura da soja (semente e adubo), aplicação de inseticida de final de ciclo, aplicação de herbicida pós-emergente, aplicação de fungicida, preventivo e curativo, colheita e transporte. $\mathrm{O}$ sistema AA difere do TR por incluir a operação de adubação a lanço de $\mathrm{P}$ e $\mathrm{K}$, na cultura de inverno, e pela operação de semeadura da soja ser realizada somente com a semente, não sendo necessária a utilização do adubo por já ter sido aplicado na cultura anterior.

Para avaliar a influência da época de semeadura na produtividade da soja, foram utilizados dados de produtividades a partir de ensaios realizados pela BOLETIM DE PESQUISA DE SOJA (2002), em municípios da região Noroeste do Mato Grosso, para duas cultivares: MGBR-46 Conquista (ciclo precoce) e BRSMT Pintado (ciclo médio). Com os dados de produtividade, realizou-se a análise de regressão que avaliou a correlação entre as variáveis produtividade e época de semeadura, a 5\% de probabilidade, para a obtenção de equações que predizem a produtividade das cultivares de soja em função de períodos de semeadura visualizados na Tabela 2.

TABELA 2. Período de semeadura, para definir a pontualidade na operação.

\begin{tabular}{ccc}
\hline \multirow{2}{*}{ Número de Semanas } & \multicolumn{2}{c}{ Semeadura } \\
\cline { 2 - 3 } & Início & Fim \\
\hline 1 & $15-10$ & $22-10$ \\
2 & $15-10$ & $29-10$ \\
3 & $15-10$ & $05-11$ \\
4 & $15-10$ & $12-11$ \\
6 & $15-10$ & $19-11$ \\
7 & $15-10$ & $26-11$ \\
\hline
\end{tabular}

Com os sistemas de produção e as equações de produtividade, desenvolveu-se um modelo em planilha eletrônica Excel® para a análise da receita líquida da cultura da soja. O fluxograma do algoritmo, elaborado a partir da simbologia proposta por OAKLAND (1994), é apresentado na Figura 1. 


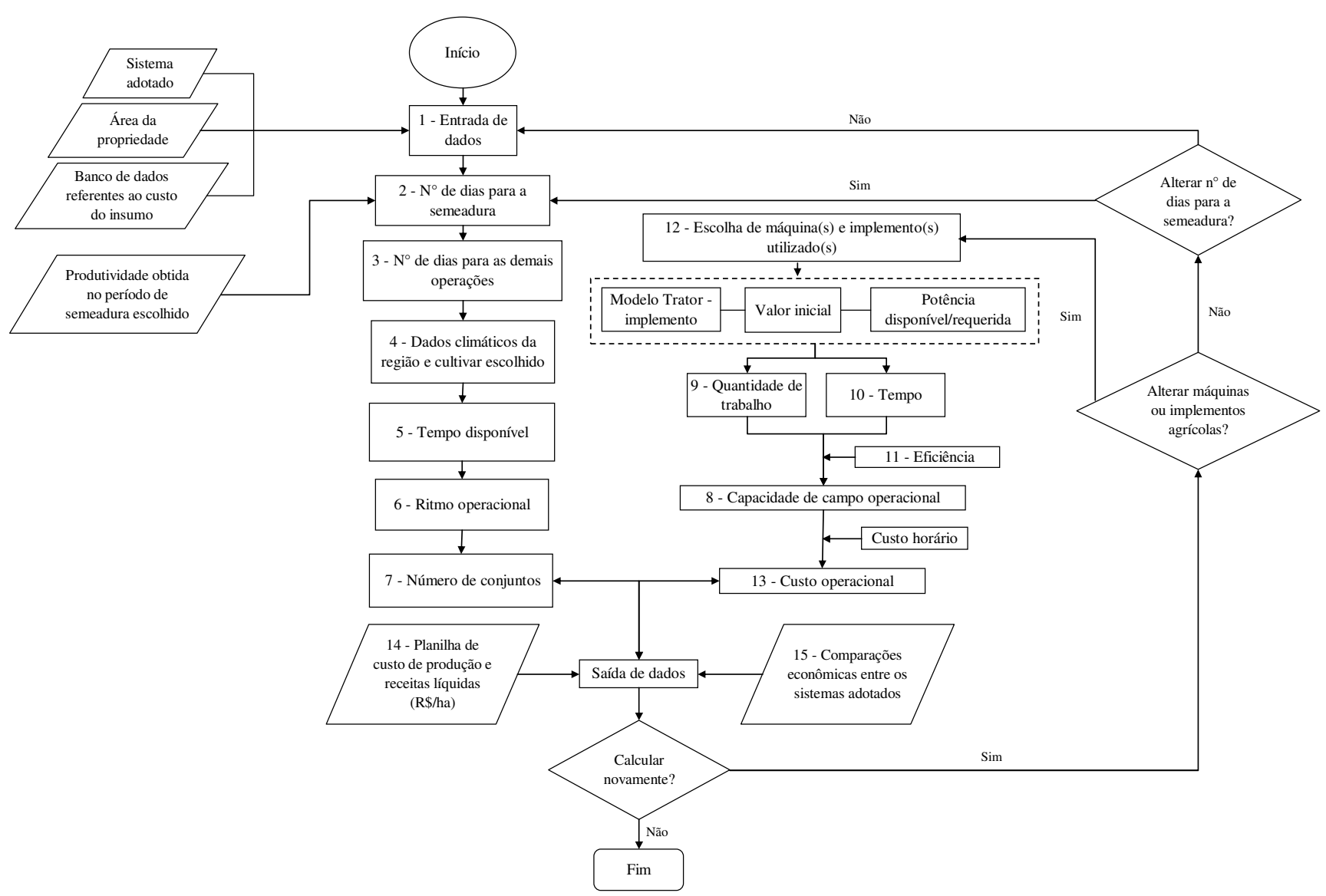

FIGURA 1. Fluxograma do modelo desenvolvido.

O algoritmo inicia-se com as entradas dos dados (1) referentes ao tamanho da área, sistemas propostos e insumos para o processo produtivo. O usuário do sistema determina o período para cada operação e, no caso da semeadura da soja (2), o modelo calcula a produtividade da cultura de acordo com as equações desenvolvidas. As datas de início e término das demais operações (3) variam de acordo com a época de semeadura escolhida. Com a entrada de dados das informações climáticas (4), dias úteis e jornada de trabalho, é calculado o tempo disponível (5). De acordo com a máquina e o implemento escolhido (12), obtém-se a capacidade de campo operacional (8), obtida pelo produto da quantidade de trabalho (9), tempo (10) e eficiência (11). Pela razão do ritmo operacional (6) e a capacidade de campo operacional (8), é calculado o número de conjuntos (7). Dessa forma, tem-se o custo operacional (14), obtido pela razão entre o custo horário (13) e a capacidade de campo operacional (8). Os resultados do modelo estão ligados em uma planilha de custos totais de produção para o cálculo da receita líquida, calculada a partir da eq.(1):

$$
\mathrm{RL}=\mathrm{RB}-\sum_{\mathrm{i}=1}^{\mathrm{n}}\left(\mathrm{CI}_{\mathrm{i}}+\mathrm{CO}_{\mathrm{i}}\right)
$$

em que,

$\mathrm{RL}$ - receita líquida da cultura, $\mathrm{R} \$ \mathrm{ha}^{-1}$;

$\mathrm{RB}$ - receita bruta obtida de acordo com a época de semeadura, $\mathrm{R} \$ \mathrm{ha}^{-1}$;

n - operações mecanizadas cadastradas pelo usuário;

$\mathrm{CI}_{\mathrm{i}}$ - custos dos insumos utilizados na operação i, $\mathrm{R} \$ \mathrm{ha}^{-1}$, e

$\mathrm{CO}_{\mathrm{i}}$ - custos operacionais do sistema mecanizado na operação i, $\mathrm{R} \$ \mathrm{ha}^{-1}$.

Os custos dos insumos utilizados no processo (adubos, inseticidas, herbicidas, fungicidas, sementes, óleos lubrificantes e combustíveis) foram obtidos em fevereiro de 2005, com base no valor de revenda em empresas da região, e a taxa de juros considerada foi de $9,8 \%$ ao ano. Os custos operacionais dos sistemas mecanizados foram calculados relacionando-se o desempenho operacional e econômico de acordo com a metodologia proposta por MILAN (2004). 
A planilha foi avaliada quanto a possíveis erros de rotina, e a validação dos resultados foi efetuada pela comparação do custo horário de tratores e colhedoras calculado pelo modelo e dos dados apresentados em AGRIANUAL (2005). Na etapa de validação, também foram confrontados os dados de número de conjuntos necessários na semeadura de soja, calculados pelo modelo com os observados em uma propriedade agrícola no município de Campos de Júlio, região Noroeste do Mato Grosso.

Estabeleceu-se um cenário-base para a análise comparativa dos sistemas propostos, caracterizado por uma propriedade de 1.500 ha e um sistema mecanizado constituído de um trator 4x2, Tração Dianteira Auxiliar (TDA), de 89,1 kW (121 cv), uma semeadora/adubadora de 4,4 m de largura, um pulverizador com barra de $25 \mathrm{~m}$, uma adubadora volumétrica com sistema de distribuição centrífuga de dois pratos giratórios e largura nominal de $5 \mathrm{~m}$, e uma colhedora automotriz com plataforma de 7,59 m.

\section{RESULTADOS E DISCUSSÃO}

As produtividades das duas cultivares de soja, em função do período de semeadura, são apresentadas na Figura 2, observando-se ajuste adequado das equações com os dados fornecidos. A cultivar BRSMT Pintado apresentou valores menores em relação à MGBR-46 Conquista, independentemente do período de semeadura. A maior produtividade no período analisado foi de $3.798 \mathrm{~kg} \mathrm{ha}^{-1}$ para a MGBR-46 Conquista, semeada no período de três semanas (15-10 a 05-11), diferença de 4,8\% quando comparada à BRSMT Pintado.

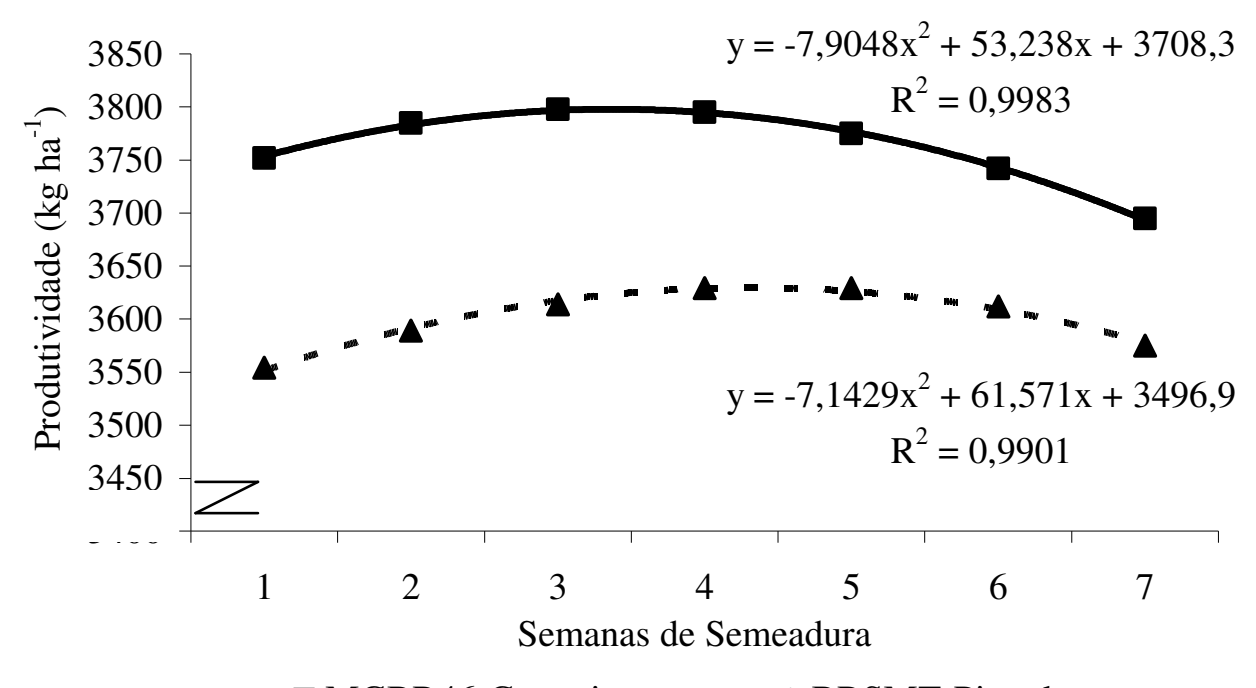

- MGBR46-Conquista

$\Delta$ BRSMT-Pintado

FIGURA 2. Produtividades das cultivares de soja em função do período de semeadura.

Na Figura 3, apresenta-se a comparação do número de conjuntos necessários para a realização da semeadura, em função do sistema utilizado e do intervalo de semeadura.

O número de conjuntos trator-semeadora aumenta de acordo com a redução do período de semeadura, devido ao menor tempo para a realização da operação (Figura 3). A adubação antecipada, sistema AA, requer menor número de conjuntos, independentemente do período de semeadura em relação ao sistema Tradicional (TR). Na semeadura realizada durante o período de uma semana (15-10 a 22-10), o sistema TR registrou 18 conjuntos; já o sistema AA, 14, diferença de $22,2 \%$. Analisando a semeadura realizada durante o período de sete semanas (15-10 a 03-12), o modelo calculou, para o sistema TR, quatro conjuntos, e para o sistema AA, 3. Em ambos os casos, a adubação antecipada reduziu o número de conjuntos e, quando se comparam os períodos de uma e sete semanas, a redução no número de conjuntos chega a 83,3\%. A comparação do custo operacional na semeadura entre os sistemas, em função do intervalo de semeadura, é apresentada na Figura 4. 


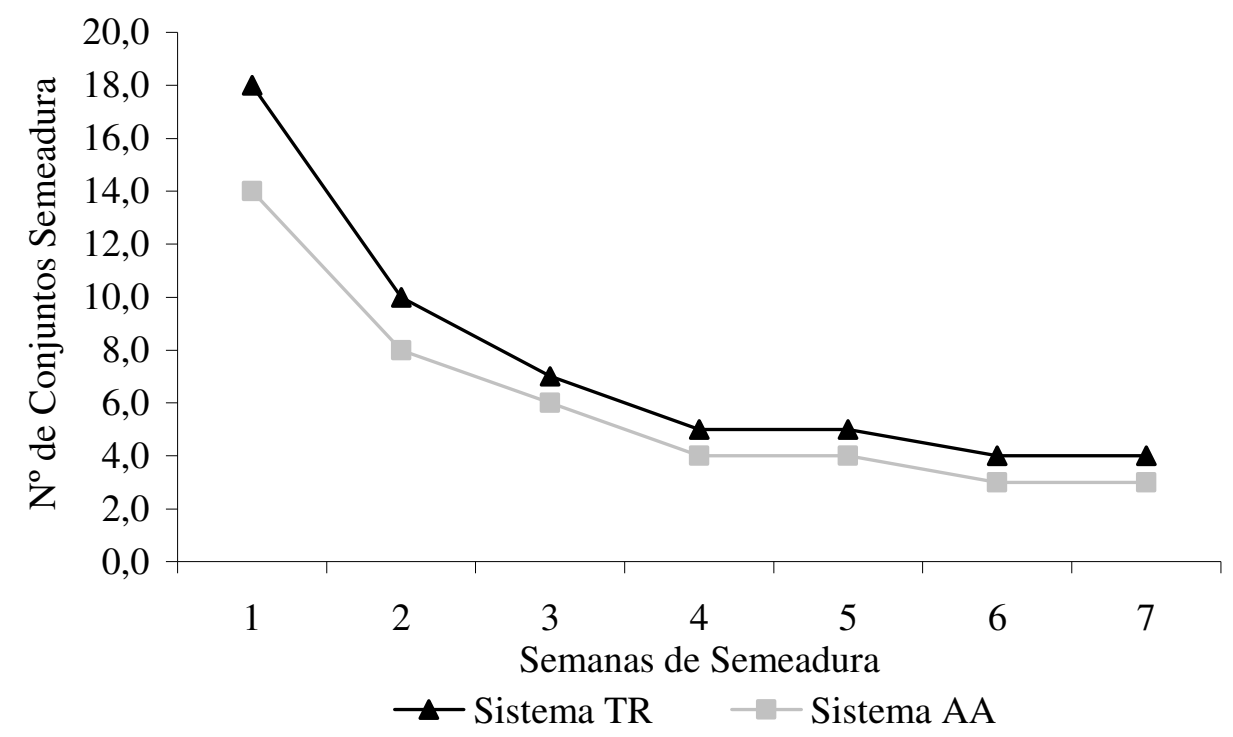

FIGURA 3. Comparação do número de conjuntos na semeadura, em função do sistema e do período de semeadura.

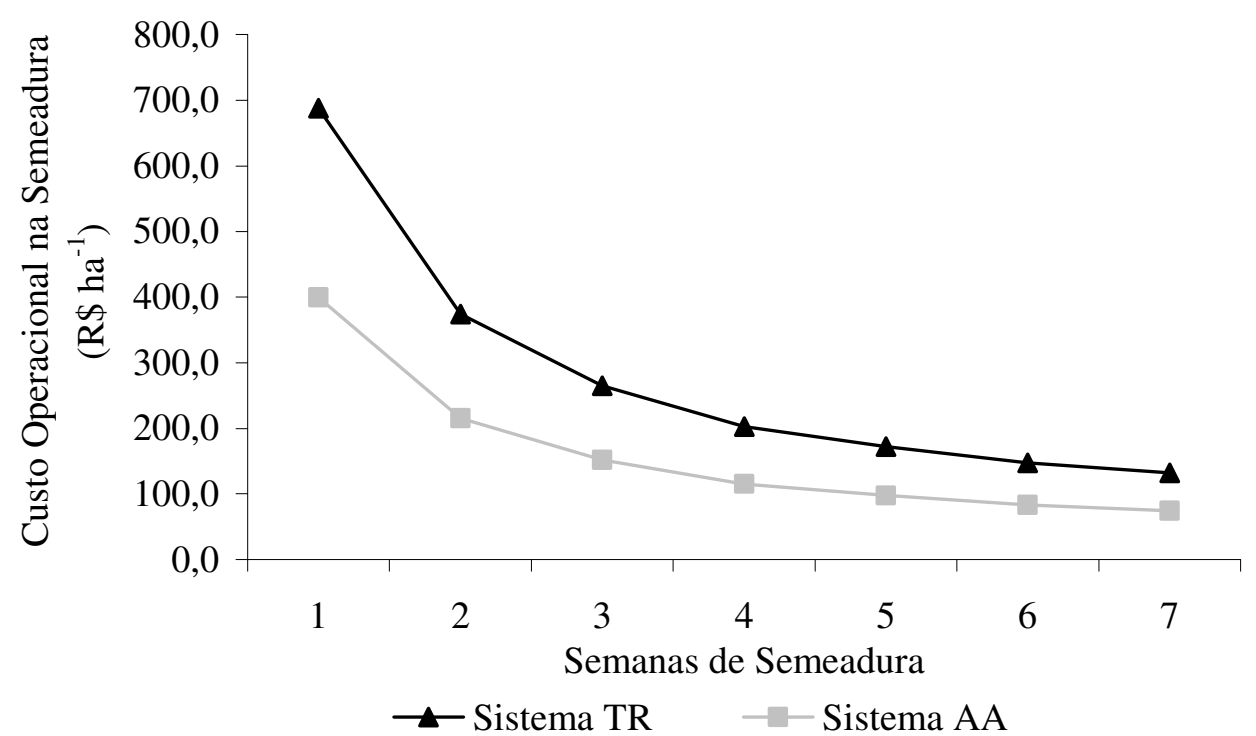

FIGURA 4. Comparação do custo operacional na semeadura em função do sistema e da época de semeadura.

O custo operacional na semeadura aumenta conforme se reduz o período da operação. $\mathrm{O}$ maior custo operacional obtido ocorreu na semeadura realizada no intervalo de uma semana (primeira época), independentemente do sistema. Para esse período, o sistema TR apresentou custo de $\mathrm{R} \$ 687,77$, e o sistema AA, de $\mathrm{R} \$ 399,55$ por hectare, com redução de $58,1 \%$ nos custos operacionais. Os menores custos operacionais ocorreram na semeadura realizada no intervalo de sete semanas, com custo por hectare de R \$ 132,79, para o sistema TR, e de R $\$ 74,28$, para o sistema AA, com redução de 55,9\% (Figura 4).

A análise comparativa do custo total obtido entre os sistemas de colheita, em função do período adotado de semeadura, é apresentada na Figura 5.

Os custos totais elevam-se com a diminuição no período de semeadura. O sistema AA apresentou menores custos totais em relação ao TR, independentemente do intervalo de semeadura. Para a semeadura realizada durante o intervalo de sete semanas, obteve-se custo total por hectare de $\mathrm{R} \$ 1.450,63$ para o sistema TR, e de $\mathrm{R} \$ 1.254,54$ para o AA, com diferença de $15,6 \%$. Em relação à semeadura realizada no período de uma semana, o sistema TR tem custo por hectare de 
$\mathrm{R} \$ 3.893,40$ contra $\mathrm{R} \$ 3.467,62$ do AA, diferença de $12,3 \%$. O aumento nos custos operacionais e totais deve-se, principalmente, à elevação nos custos de colheita, devido à necessidade de maior número de máquinas para a operação e à diminuição das horas trabalhadas, o que implica elevação do custo fixo das colhedoras (Figura 5).

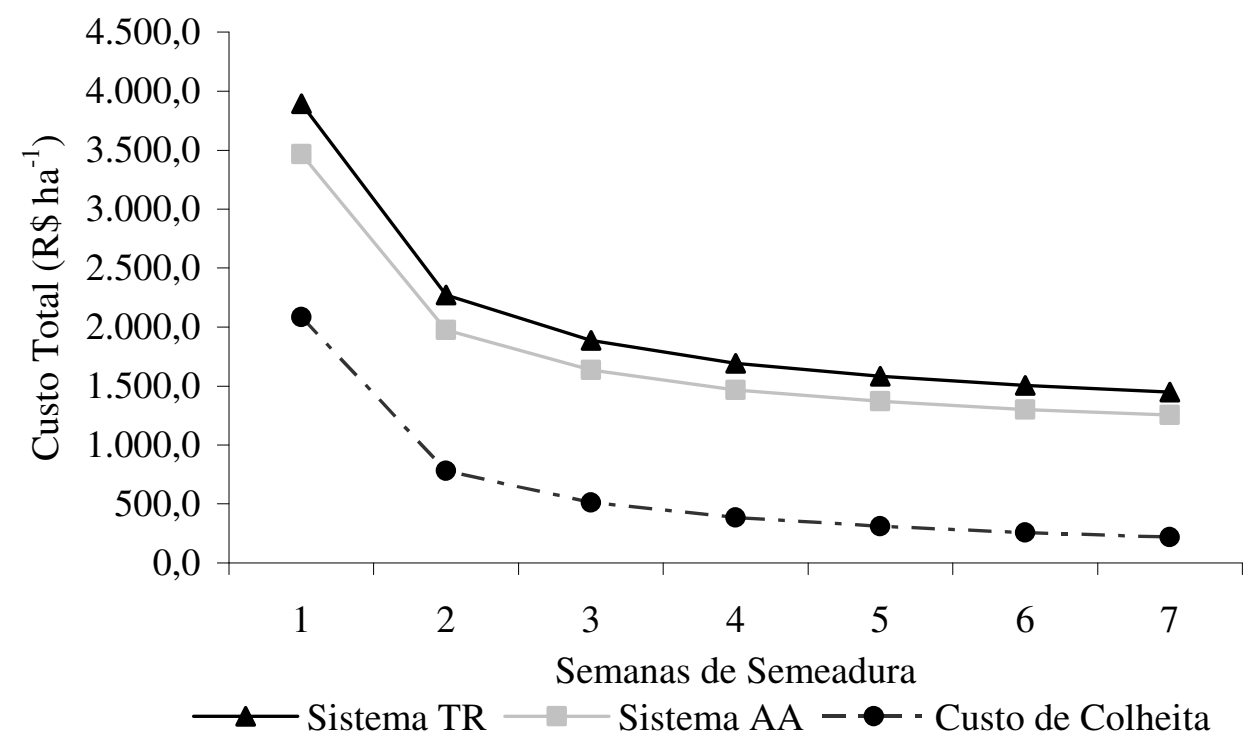

FIGURA 5. Comparação do custo total e de colheita em função do sistema e da época de semeadura.

A análise da receita líquida obtida com a consideração do sistema adotado e do intervalo de semeadura para o valor de $\mathrm{R} \$ 21,00$, na saca da soja, é mostrada na Figura 6.

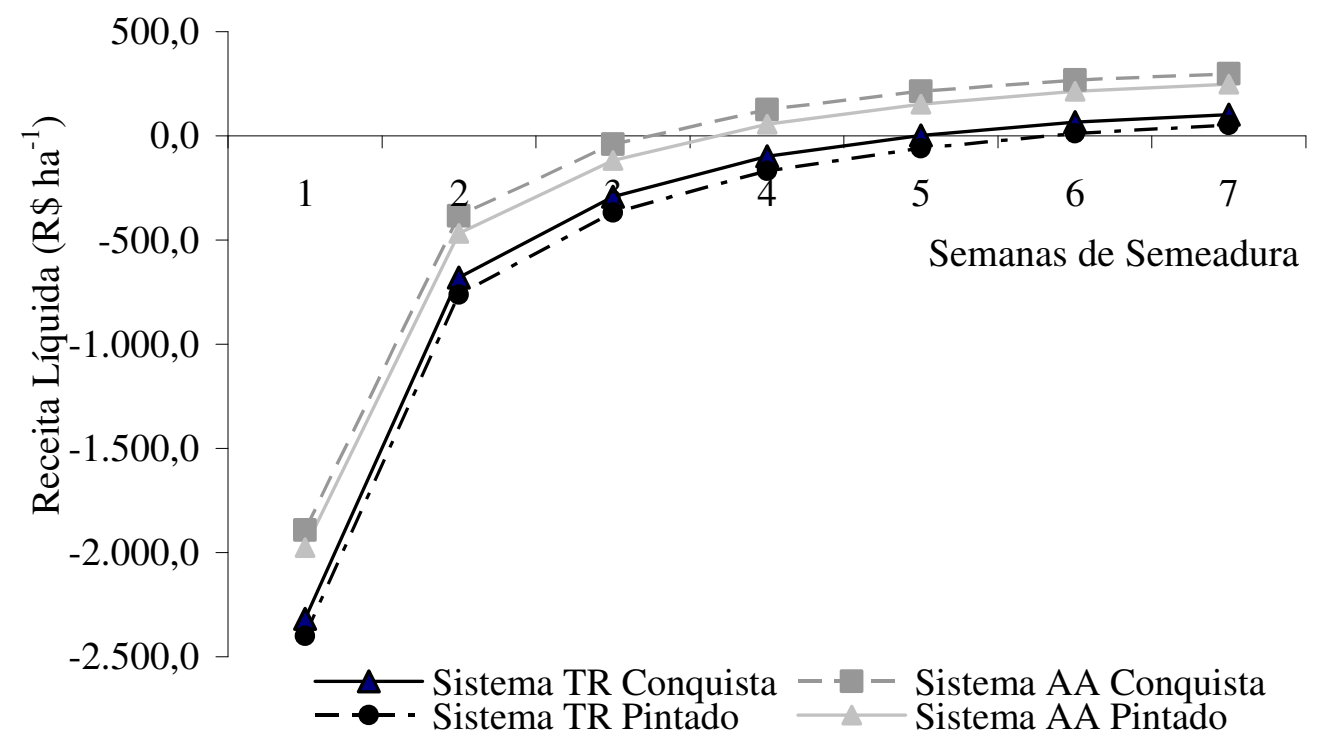

FIGURA 6. Análise da receita líquida em função da cultivar, do sistema e do intervalo de semeadura.

Em relação à renda líquida obtida, o sistema AA apresentou renda líquida positiva a partir do quarto período de semeadura (Figura 6). Com a diminuição do período de semeadura, a renda líquida torna-se mais negativa, fator que está associado ao maior número de conjuntos necessários para atender à demanda. A receita líquida prevista por hectare para a semeadura realizada na primeira semana para a cultivar MGBR-46 Conquista foi negativa, com valor de R $\$-2.317,62$ por hectare para o sistema TR e R \$ $1.891,83$ para o AA, com este último apresentando melhor retorno, independentemente da cultivar e do período de semeadura quando comparado ao TR. Ainda 
analisando a Figura 6, as maiores receitas líquidas obtidas por hectare foram de R $\$ 297,44$, para a cultivar MGBR-46 Conquista, semeada no intervalo de sete semanas (15-10 a 03-12), e de R\$ 268,56, para a mesma cultivar semeada no intervalo de seis semanas (15-10 a 26-11), ambas no sistema AA, redução de $9,71 \%$ na receita líquida entre os intervalos de semeadura.

Na Figura 7, visualiza-se a análise de alterações nas receitas líquidas, em função do sistema e do intervalo de semeadura, considerando-se o mês de fevereiro em dois anos consecutivos.

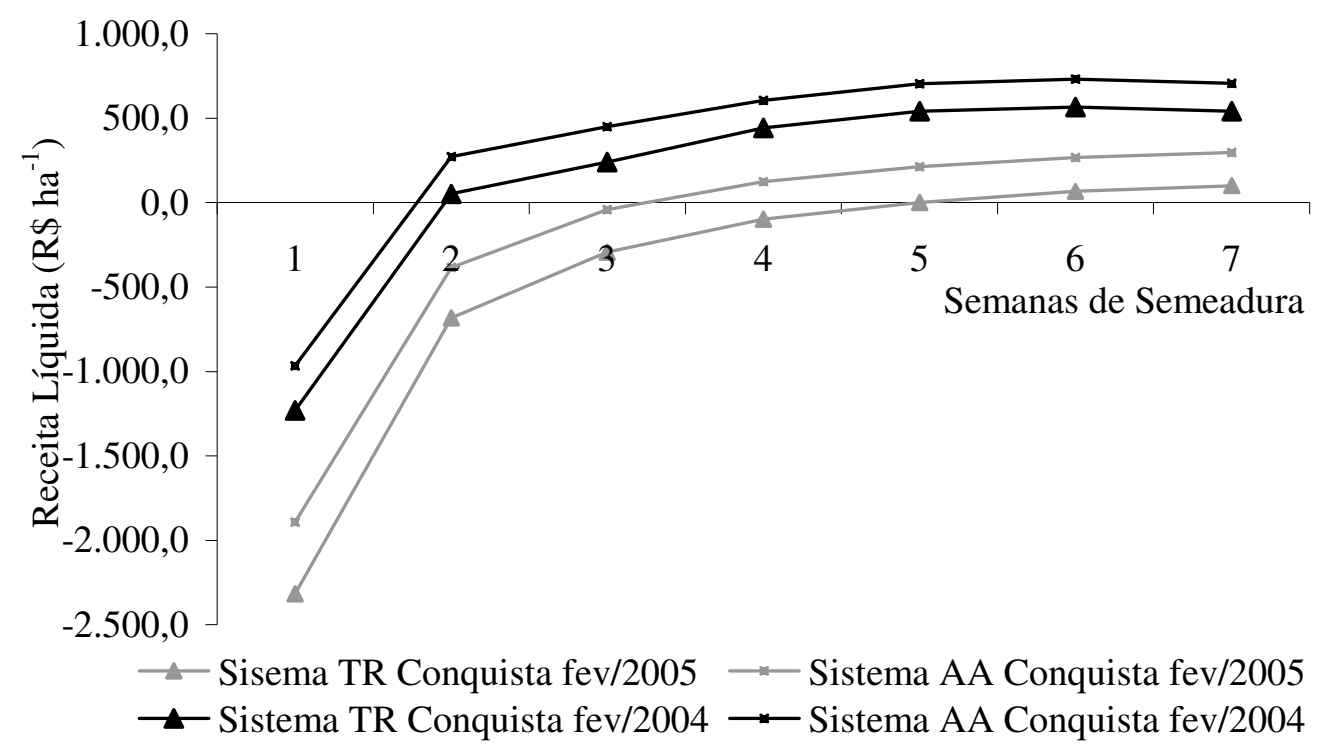

FIGURA 7. Análise de alterações das receitas líquidas em função do sistema e do intervalo de semeadura, para valores observados em fevereiro de 2004 e fevereiro de 2005.

As modificações sobre o preço da saca da soja provocaram alterações na rentabilidade da cultura quando analisado o seu valor no município de Campos de Júlio, em dois períodos: $\mathrm{R} \$ 41,50$ em fevereiro de 2004 e R \$ 21,00 em fevereiro de 2005 (Figura 7). A cultivar MGBR-46 Conquista mostrou receita líquida por hectare de $\mathrm{R} \$ 706,60$, considerando o sistema AA e o intervalo de sete semanas, em fevereiro de 2004. Em relação a fevereiro de 2005, a receita líquida foi de $\mathrm{R} \$ 297,44$, para o mesmo sistema e época de semeadura, redução de 42,09\%. Quando do uso do sistema de antecipação da adubação, a renda líquida é positiva a partir de um período de duas semanas de semeadura, em 2004, e de quatro semanas, em 2005, evidenciando a viabilidade de antecipar a adubação nas condições propostas pelo trabalho.

\section{CONCLUSÕES}

As produtividades das cultivares foram afetadas pela época de semeadura, caracterizando a importância de se considerar a pontualidade para a operação de semeadura.

O modelo desenvolvido permite analisar as influências da época de realização da operação de adubação no desempenho operacional e econômico dos sistemas mecanizados e na renda líquida da cultura da soja, considerando-se a pontualidade na semeadura.

O sistema de antecipação da adubação para a cultura da soja é viável, reduzindo o número de conjuntos, os custos operacional e total, e possibilita o aumento na receita líquida, quando comparado ao sistema tradicional, independentemente do período de semeadura.

\section{REFERÊNCIAS}

ABIOVE. Associação Brasileira das Indústrias de Óleos Vegetais. Perspectivas de mercado para a soja. Disponível em: <www.abiove.com.br>Acesso em: 15 mar. 2005.

AGRIANUAL 2005: anuário estatístico da agricultura brasileira. São Paulo: FNP Consultoria e Comércio, 2004. 544 p. 
BALASTEREIRE, L. A. Máquinas agrícolas. São Paulo: Manole, 1987. 307 p.

BOLETIM DE PESQUISA DE SOJA, 6, Rondonópolis: Fundação MT, 2002. 238 p.

CÂMARA, G.M.S. Fisiologia, ambiente e rendimento. In: CÂMARA, G.M.S. (Ed.) Soja: tecnologia da produção II. Piracicaba: ESALQ, Departamento de Produção Vegetal, 2000. p. 81120.

EMPRESA BRASILEIRA DE PESQUISA AGROPECUÁRIA. Centro Nacional de Pesquisa de Soja: Recomendações técnicas para a cultura da soja na região central do Brasil. 1997-1998. Londrina, 1997. 171 p. (Documentos, 106).

FRANCISCO, E.A.B. Antecipação da adubação da soja na cultura de Eleusine coracana (L.) Gaertn., em sistema de plantio direto. 2002. 58 f. Dissertação (Mestrado em Fitotecnia) - Escola Superior de Agricultura "Luiz de Queiroz", Universidade de São Paulo, Piracicaba, 2002.

MATOS, M.A.; SALVI, J.V.; MILAN, M. Avaliação do custo indireto da pontualidade na semeadura direta da soja (Glycine Max (L.) Merril) através da antecipação da adubação. In: CONGRESSO BRASILEIRO DE ENGENHARIA AGRÍCOLA, 34., 2005, Canoas. Anais... Jaboticabal: Associação Brasileira de Engenharia Agrícola, 2005. 1 CD-ROM.

MILAN, M. Gestão sistêmica e planejamento de máquinas agrícolas. 2004. $100 \mathrm{f}$. Tese (LivreDocência em Mecânica e Máquinas Agrícolas) - Escola Superior de Agricultura "Luiz de Queiroz", Universidade de São Paulo, Piracicaba, 2004.

OAKLAND, J.S. Gerenciamento da qualidade total. São Paulo: Nobel, 1994. 459 p.

VEIGA, M.G. Modelo empírico para a seleção de máquinas agrícolas na cultura da soja considerando a pontualidade na semeadura. 2000. 75 f. Dissertação (Mestrado em Máquinas Agrícolas) - Escola Superior de Agricultura "Luiz de Queiroz", Universidade de São Paulo, Piracicaba, 2000.

WITNEY, B. Choosing and using farm machines. Essex: Longman Scientific and Technical, 1998. $412 \mathrm{p}$. 